\title{
ORIENTACIONES TRANSANDINAS PARA LOS ESTUDIOS ANDINOS ${ }^{1}$
}

\author{
POR \\ Vicente Bernaschina Schürmann y Marco Thomas Bosshard \\ Europa-Universität Flensburg
}

A partir de los debates de fines del siglo XX y principios del XXI sobre la globalización, los estudios regionales o de área y distintos fenómenos transnacionales, proponer una orientación transandina para los estudios literarios y culturales latinoamericanos pareciera ser un gesto muy adecuado a los tiempos que corren. ${ }^{2} \mathrm{Un}$ gesto bueno y deseable, pero que es necesario abordar con cuidado para no caer bajo el imperio de ciertas modas y desatender, en consecuencia, los desafíos específicos que emergen desde las culturas y literaturas en la región andina y en relación con ella.

La acelerada y creciente interconexión política, económica y cultural del planeta, propiciada por los avances tecnológicos en los medios de transporte y de comunicación, junto a los intercambios y flujos de mercancías, capitales, servicios y seres humanos, fomentados por el capitalismo neoliberal, no han dejado inerme a la cultura andina. Lo que durante la primera mitad del siglo XX se percibiera en países como Perú, Bolivia o Ecuador como las desastrosas consecuencias de la modernización y de las migraciones de la sierra o de la selva a la ciudad, se perfilaría hacia las décadas de los setenta y ochenta como una diáspora hacia otros centros metropolitanos fuera de las fronteras nacionales, en búsqueda de mejores posibilidades laborales o espacios de

1 Los editores agradecemos a todos los participantes tanto de las mesas del Congreso anual del Instituto Internacional de Literatura Iberoamericana (IILI) en Cádiz (2012) y en las Jornadas Andinas de Literatura Latinoamericana (JALL) en Cali (2012), así como del Simposio internacional Estudios transandinos en la Ruhr-Universität Bochum (2013). Sin su colaboración y entusiasmo, esta publicación no hubiera tomado el impulso que finalmente tomó. Se agradece también al Fondo Nacional Alemán de Investigación (DFG) y a la Fundación Mercator, cuyo apoyo económico nos permitió la organización de un simposio transandino alemán. Finalmente, se agradece a Juan Duchesne, Elizabeth Monasterios y a todo el equipo del Instituto Internacional de Literatura Iberoamericana por el apoyo para esta publicación.

2 Ver por ejemplo Appadurai; Báez Hernández; Cortés y Torres; Hall y Tarrow; Portes, Guarizo y Landolt; Pries; Vertovec, etc. 
vida menos violentos. ${ }^{3}$ Por otra parte, las pocas (sino nulas) capacidades de los Estados nacionales para representar política y culturalmente a diversos pueblos indígenas que de suyo habitan regiones del continente que no calzan con las fronteras de la nación, han derivado en lo que Françoise Morin y Roberto Santana han denominado el desafío transnacional para los pueblos autóctonos.

Hablar de estudios transandinos a partir de estos fenómenos permitiría destacar al menos tres cosas: primero, las transformaciones que experimentan las prácticas culturales andinas en su diáspora internacional; segundo, las identificaciones estratégicas y utilizaciones de ciertos discursos indígenas por parte de los migrantes para afianzar su lugar en el extranjero; tercero, el aprovechamiento de instituciones y medios proporcionados por la globalización para la creación de nuevos lazos y solidaridades entre diversas comunidades y actores marginalizados (entre ellos también los pueblos indígenas) más allá de las fronteras nacionales. Sin embargo, con esta orientación de eminente carácter cultural, se corre el riesgo de subordinar cualquier fenómeno transandino bajo el paradigma de la globalización transnacional. Lo que resulta problemático, no sólo por el mayor peso que tienen en estas perspectivas las miradas desde y hacia el hemisferio norte (principalmente la emigración hacia Europa o los Estados Unidos), olvidando las relaciones transnacionales dentro del mismo espacio andino o con regiones colindantes, sino también por el problema histórico que representa la mirada transnacional. Los nuevos lazos y solidaridades que crean las diversas comunidades andinas surgen como respuestas a la desprotección en la que viven al no subsumirse a las representaciones ofrecidas por los Estados nacionales, lo que no es algo que se manifieste del mismo modo a lo largo del periodo que va desde el nacimiento de la nación moderna hasta los inicios del siglo XXI, ni tampoco homologable con las relaciones que ya habían establecido estas comunidades en tiempos precolombinos o luego de la Conquista y el Virreinato.

Para evitar el anacronismo que amenaza ciertas teorizaciones culturales, parece necesario separar la orientación transandina del enfoque transnacional (pos)moderno por tres razones: primero, porque no abandona el foco andino y reconoce así el carácter plural de este complejo cultural en su historia desde los pueblos precolombinos, incluso antes de la instalación del Tahuantinsuyo. Segundo, porque con el prefijo trans, esta perspectiva implica los procesos históricos fomentados por la Colonia y por el nacionalismo moderno, que llevaron a la dispersión, fragmentación y rearticulación de las culturas andinas (sean estas de carácter elitista, popular o indígena) que así resultaron, en diversos momentos, restringidas a nuevas fronteras administrativas y culturales. Tercero, porque bajo esta mirada histórica, la orientación transandina

Para el caso del Perú, ver Zevallos, "Hacia una topografía” y, recientemente, Noriega Bernuy. Ver también la colaboración de Zevallos en este volumen.

Revista Iberoamericana, Vol. LXXXI, Núm. 253, Octubre-Diciembre 2015, 925-935 ISSN 0034-9631 (Impreso)

ISSN 2154-4794 (Electrónico) 
no reduce la indiscutible diversidad que pervive al interior de las distintas naciones andinas a relaciones entre Estados y evita pensar esta heterogeneidad interna como una acumulación de esferas estáticas o como hibrideces fronterizas modeladas en el ejemplo de México y su cercanía inmediata con los Estados Unidos. ${ }^{4}$

En otras palabras, lo que una orientación transandina intenta destacar en sus indagaciones culturales es la pervivencia de al menos cuatro articulaciones históricas entrelazadas, a veces superpuestas, aunque no sustitutivas y que afectan determinantemente las prácticas y discursos andinos. A saber, una primera articulación (por supuesto no exenta de conflictos) entre las diversas comunidades indígenas del altiplano andino y regiones colindantes, que son las primeras en construir la región andina como un complejo cultural común; una segunda, con la instalación del Virreinato del Perú y sus diversos mecanismos institucionales de administración y control (provengan estos de la Corte, la Inquisición, las misiones, o las distintas reducciones indígenas) sobre las dinámicas culturales precedentes; una tercera, marcada por la fragmentación de la zona andina en Estados nacionales, en la que destacan discursos nacionalistas, indigenistas y americanistas; y una cuarta, caracterizada por las migraciones y "diásporas" intra, inter y transnacionales.

\section{II}

Hasta el momento, hemos propuesto aspectos generales de orden cultural que caracterizan una orientación transandina. Sin embargo, creemos también que esta orientación tiene un potencial acaso mayor en lo que se refiere a prácticas y discursos poético-literarios. Durante gran parte del siglo XX, la crítica literaria latinoamericana ha sospechado que el marco ofrecido por los Estados nacionales es insuficiente para dar cuenta de la interpretación del mundo que ofrecen las literaturas (o sistemas literarios) en el continente. En una dimensión diacrónica, el enfrentamiento de sustratos indígenas y coloniales conforman matrices culturales y literarias homólogas en distintas regiones que han invitado en el transcurso de la historia a un trabajo creativo y crítico regional, continental y en algunos casos incluso global; en una dimensión sincrónica, existen relaciones intelectuales americanas que no se condicen con los intereses de la nación y que buscan fortalecer los vasos comunicantes entre distintos espacios culturales del continente.

Para no ir demasiado lejos y empezar largas arqueologías, baste señalar que hacia la década de los sesenta, Ángel Rama declaraba su sospecha de que la totalidad socioliteraria -la exigencia metodológica para abordar la articulación de los sistemas

4 Estas consideraciones (y otras relacionadas) se hayan expuestas con mayor detalle en Bosshard, "Estudios transandinos".

Revista Iberoamericana, Vol. LXXXI, Núm. 253, Octubre-Diciembre 2015, 925-935 ISSN 0034-9631 (Impreso)

ISSN 2154-4794 (Electrónico) 
literarios y la sociedad latinoamericana- no tenía por qué coincidir con la patria (Rojo 12). Es más, en América Latina, la idea de la existencia necesaria de sistemas literarios nacionales no sólo proviene de la balcanización política del continente debido a los imperialismos, las oligarquías locales y las administraciones impuestas por el coloniaje, sino además resulta una categoría que no permite la actuación de otras configuraciones más "auténticas": a saber, "la natural expansión y desarrollo de las comarcas semejantes, donde los elementos étnicos, la naturaleza, las formas espontáneas de la sociabilidad, las tradiciones de la cultura popular, convergen en parecidas formas de creación literaria" (citado por Rojo 15). Estas comarcas son, según Rama, el Tahuantinsuyo, la Pampa y el Caribe, donde la primera será el campo en el que centrará su propuesta de la transculturación literaria.

Este problema, la necesidad de encontrar un marco de interpretación literario distinto a la nación y más de acuerdo con las condiciones políticas y culturales de la sociedad desde la que surge, será el tema central de los debates teóricos de las décadas siguientes. Así, hacia 1975, Roberto Fernández Retamar, hablando también de la balcanización del continente, sugerirá el modelo de la "otra" Europa para encontrar homologías estructurales y políticas para comprender la totalidad socioliteraria y la "situación particular" latinoamericana (Fernández 99-103), mientras que Antonio Cornejo Polar, a partir de la década de los ochenta, propondrá indagar los procesos heterogéneos que conforman la "totalidad contradictoria" que es la literatura peruana. El énfasis en el proceso, que es distintivo en Cornejo Polar, no es sólo un imperativo para historiar la literatura, sino una comprensión de las tradiciones literarias en el tiempo que engarza aporéticamente proceso, estructura y lectura: aquello que en Escribir en el aire denomina "historiar la sincronía" (11) y que en trabajos anteriores, se podía apreciar en sus advertencias sobre "la naturaleza agudamente ideológica" de la historia y en el complejo movimiento de las tradiciones. A saber: proceso en el que la "objetividad" del acontecer histórico se entrevera con el "modo como lo leen en cada circunstancia los distintos grupos sociales. A la postre, la tradición es producto de esta lectura que no solamente establece el sentido del pasado, sino también -y a veces más- el del presente" (Cornejo, La formación 15).

Observando estos aportes de la crítica literaria -que necesariamente fracasarán como teoría específicamente latinoamericana (Cornejo, "Para una teoría"9)-, podemos reconocer de qué modo prácticas y discursos poético-literarios son de una importancia fundamental para una orientación transandina. Por una parte, se plantea un marco general que invita a comprender la constitución de ciertas áreas socioculturales o comarcas no en su estancamiento o en su aislamiento perpetuo, sino a partir de las relaciones dinámicas y alternantes que sostienen las unas con las otras dentro de la historia. Por otra parte, vemos que ese marco general, en cuanto configuración de una totalidad, se demuestra siempre provisorio, porque pone a prueba su "objetividad" en la práctica de la lectura que hacen de él los distintos grupos sociales.

Revista Iberoamericana, Vol. LXXXI, Núm. 253, Octubre-Diciembre 2015, $925-935$ ISSN 0034-9631 (Impreso)

ISSN 2154-4794 (Electrónico) 
A la luz de las dinámicas poético-literarias y de las configuraciones de lectura, queda en evidencia que para comprender los complejos entramados culturales desde una orientación transandina no basta con la dimensión cultural por sí sola, no basta con afirmar la sola existencia de etnias transnacionales, diásporas políticas o laborales, o redes de intercambios intelectuales concretos. ${ }^{5}$ Fenómenos como estos pertenecen a una perspectiva transandina, pero no son causa suficiente para determinarla. Son de principal interés para enfoques culturales, etnológicos, antropológicos o sociológicos, pero tienden a relegar a un segundo plano la capacidad transformadora de la literatura, su participación decisiva en la construcción de espacios, historias y políticas para las comunidades desde las que emergen, a las que se revierten y las que a su vez proyectan continuamente. Un enfoque transandino, entonces, no consiste en establecer primero dos o más entidades más o menos fijas, sean estas áreas, regiones o naciones, para luego ver si existen o no ciertas homologías estructurales o ciertos intercambios de saberes; ni tampoco en determinar ciertas épocas que se han ido sustituyendo, dejando acaso para nuestro presente algunas huellas o monumentos desvinculados de prácticas y discursos; el énfasis está puesto, más bien, en una configuración determinada, es decir, en el continuo proceso en el que determinadas prácticas y discursos culturales se constituyen en función de otros con los que dialogan o a los que se contraponen, a la vez que son leídos y releídos por una comunidad que se recrea a sí misma en ese contrapunto hermenéutico e histórico.

En este sentido, desde la dimensión poético-literaria de la orientación transandina, cabe destacar dos cosas. Primero, la insistencia en la noción de literatura, porque en ella perviven proyectos modernos y ciudadanos fundamentales (Rincón 34 y Zevallos, Las provincias 17-18), que no es posible remitir a un tipo más entre otras prácticas culturales, como tampoco subsumir a discursos o semiosis coloniales (Cornejo, Escribir 22). La literatura, en cuanto práctica histórica -y no como esencia humana (una cosa no quita

\footnotetext{
5 Para una propuesta reciente sobre "sujetos y textos transandinos", ver Caminan los Apus, de Julio E. Noriega Bernuy. Ante la coincidencia nominal, es necesario aclarar que el estudio de Noriega se dedica a definir la poética del sujeto migrante andino en la etapa actual de la globalización, rastreando actividades poéticas que conjuntan un sustrato lingüístico y cultural "andino", otro "peruano" y un tercero, en su caso, el "inglés estadounidense". De tal forma, Noriega Bernuy aclara que "para comprender al andino transnacional, al migrante que trasciende los Andes, en cuya identidad heterogénea se alternan varios individuos, me permito proponer, por analogía con el término transnacional y por préstamo de una palabra de las letras de un huayno, la denominación de sujeto transandino como la que mejor define su condición de sujeto migrante en triple desplazamiento" (29-30). Para estudios sociológicos sobre relaciones transnacionales en la región andina, como en la zona del trapecio andino o en la región norte de Chile y el sur de Bolivia y del Perú, ver Morin y Santana. Para encuentros de escritores chilenos y bolivianos, como el caso del encuentro literario Surescrituras, ver algunos de los documentos recopilados en: http://www.letras.s5.com/archivosurescrituras.htm (consultado 26-06-12). Sobre el proyecto editorial y de la revista virtual Cinosargo, radicados en Arica y en los que se unen escritores chilenos y peruanos, ver: http://www.cinosargo.com y http://www.cinosargo.cl (26-06-12).
}

Revista Iberoamericana, Vol. LXXXI, Núm. 253, Octubre-Diciembre 2015, $925-935$ ISSN 0034-9631 (Impreso) ISSN 2154-4794 (Electrónico) 
la otra, pero no es posible olvidar los puntos en que ambas perspectivas difieren)-, es en nuestras regiones de suyo colonial, pero también, y he aquí un punto fundamental, siempre algo más. Ese exceso de la literatura, que tiene que ver con aspectos formales, estructurales y estéticos, es el que se pone en tensión constante con las tradiciones en América Latina que intentan homogeneizarla, singularizarla y afincarla a los procesos de construcción nacional.

Segundo, dejar claro que una configuración transandina, siempre esporádica y provisoria, no es una mutación eterna y completamente indeterminable. Por su determinación histórico-cultural, la configuración transandina no se propicia sin la historia de los Estados nacionales, aunque no es consecuencia de ellos. Los antecede como posibilidad, pero no se articula hasta que entra en conflicto con ellos. La configuración emerge de la multiplicidad de tradiciones e historias - discontinuas y heterogéneas-que, sin obviar los eventos de la Conquista y las independencias, tampoco se reducen a esa narración teleológica en que se ha convertido la historia de América Latina. Quizás mediante esta perspectiva sea posible releer la persistencia en diversas tradiciones de las propuestas de Mariátegui, Vallejo, Churata, Borda y Arguedas, entre otras, y reconfigurar nuestro presente, en palabras de Cornejo Polar, "como hechura trágica que convierte su vasta pluralidad de contradicciones en una deslumbrante opción de plenitud" (La formación 155). ${ }^{6}$

Entre julio y agosto de 2012, en el marco del Congreso del Instituto Internacional de Literatura Iberoamericana en Cádiz y de las Jornadas Andinas de Literatura Latinoamericana de Cali, se reunieron por primera vez distintos investigadores de América Latina, Estados Unidos y Europa para abordar las posibilidades de colaborar sobre temáticas transandinas. Algunas de las ideas formuladas en esta introducción fueron fruto de las contribuciones a los paneles de discusión y de los debates suscitados. El interés por continuar y consolidar este diálogo condujo a la celebración en febrero de 2013 de un simposio internacional en la Ruhr-Universität Bochum bajo el título de Estudios Transandinos. A este simposio no sólo asistieron los investigadores que ya habían conformado los paneles en Cádiz y Cali, sino que se agregaron además otros

6 Estas ideas, puestas en relación al análisis de poéticas particulares que a primera vista no pertenecen a la zona andina en un sentido tradicional, sino a la literatura chilena o a la literatura mapuche, están desarrolladas en Bernaschina, "Estudios transandinos". Para una lectura que destaca los intercambios y relaciones entre el Brasíl y la región andina, ver Hernando, "Antropólogos/Antropófagos". Otra propuesta, focalizada en la poética de Cecilia Vicuña y en las metáforas textiles transandinas, se encuentra en Carggiolis, "Tejidos y anudados poéticos".

Revista Iberoamericana, Vol. LXXXI, Núm. 253, Octubre-Diciembre 2015, 925-935 ISSN 0034-9631 (Impreso)

ISSN 2154-4794 (Electrónico) 
especialistas provenientes de Alemania, Italia, Holanda, México y que contribuyeron a enriquecer la propuesta con perspectivas literarias, sociológicas y lingüísticas.

Algunas de las contribuciones presentadas en Bochum son las que se ofrecen en este número monográfico de la Revista Iberoamericana. En su conjunto, estos artículos no tienen la pretensión de fundar un nuevo campo de estudios o de conformar nuevos conceptos teóricos; la invitación fue, más bien, a adoptar un modo de lectura que intentara impulsar o problematizar la orientación transandina que se había comenzado a discutir en los encuentros anteriores, probando la pertinencia y tal vez la viabilidad de un enfoque como éste tanto en su dimensión cultural como literaria.

Precisamente sobre esta pertinencia es que la colaboración de Pablo Valdivia Orozco plantea que la reflexión sobre perspectivas transandinas no es o no debe ser mera constatación de un hecho literario y cultural complejo que se sobrepondría a los estudios andinos y para el cual se requerirían una determinada epistemología y determinados métodos de investigación. La pregunta por estudios de orientación transandina responde, más bien, a un problema de la relación entre teoría y crítica o, como él lo denomina, de constelaciones y configuraciones. Así, siguiendo ciertos planteamientos teórico-culturales de Antonio Cornejo Polar, Bolívar Echeverría y José María Arguedas, Valdivia dice que el aporte transandino consistiría en narrar una configuración con una visión teórica, aspirando a una totalidad sin deshacerse de su especificidad. Es decir, narrar los modos en que la especificidad andina se abre a una posible constelación transandina, en constante interacción con la aspiración universal que caracteriza a toda teoría.

En relación con estas configuraciones de lectura, Ulises Juan Zevallos Aguilar y Marco Thomas Bosshard vuelcan su atención a la metáfora metodológica del archipiélago cultural. Zevallos, revisando trabajos anteriores sobre esta figura, ofrece un fundamental panorama histórico de los usos que se han hecho del modelo archipiélico para destacar ciertas particularidades de la sociedad andina (John V. Murra), de los sistemas literarios del Perú (Cornejo Polar), de las relaciones internacionales de la vanguardia andina (David Wise) y de los procesos de la conformación de una cultura migrante y transnacional.

Bosshard, por su parte, llama la atención sobre las posibles filiaciones caribeñas del "archipiélago vertical" en los estudios etnográficos de John V. Murra con el fin de comparar el uso de la metáfora con las propuestas del poeta y teórico cultural martiniqués Édouard Glissant. La comparación permite no sólo apreciar en la lectura archipiélica de Murra la presencia de una dimensión transareal y transandina en las descripciones de las culturas previas al incanato, sino además observar en qué casos la metáfora impulsa un modelo de organización política y ecológica que fomenta la convivencia de culturas diferentes y en qué otros, fomenta la creación poética de un espacio cultural.

Revista Iberoamericana, Vol. LXXXI, Núm. 253, Octubre-Diciembre 2015, $925-935$ ISSN 0034-9631 (Impreso)

ISSN 2154-4794 (Electrónico) 
Un intelectual y escritor insoslayable para un enfoque transandino en la literatura parece ser Gamaliel Churata y su colosal obra El pez de oro. No sólo por razones biográficas, sino además por la dimensión histórica y cultural que tiene su obra dentro del contexto de las vanguardias, de los discursos indígenas e indigenistas y de una crítica radical a los Estados nacionales en la región andina. Elizabeth Monasterios destaca, en este sentido, junto con la obra de Arturo Borda, la contramarcha vanguardista que ofrece Churata como proyecto de crítica al Estado de características occidentales y la labor educativa que reclama para el indio desde el indio. Un proyecto crítico cultural que se remonta hasta la escritura de Felipe Guamán Poma de Ayala y que pone en tensión cualquier intento posible por reapropiar a su autor y su escritura dentro de los cánones nacionales, sean estos bolivianos o peruanos.

Helena Usandizaga, por su parte, profundiza en El pez de oro, identificando los aspectos rituales o chamánicos quechuas y aymaras que poseen un carácter central en la estructuración de la obra, en la imagen del ser humano y en la comprensión del mundo que ésta ofrece. La identificación de estos rituales en la obra de Churata resulta un desafío importante, puesto que no sólo no se adecúan a las literaturas o vanguardias nacionales que intentan ofrecer un marco de inscripción para esta, sino porque Churata activa estos rituales en el texto, transformándolos a su vez en herramientas de reflexión filosófica y, por lo tanto, en diálogos abiertos con otros momentos históricos y con otros sistemas de pensamiento.

Meritxell Hernando Marsal se detiene también en El pez de oro para ofrecer una posible lectura de su estructura a partir de las prácticas textiles andinas. Así, Hernando comienza interpretando las imágenes y el discurso presentado por Guamán Poma de Ayala sobre las mujeres tejedoras para establecer la centralidad del textil en la cultura andina. Luego, observa cómo esta práctica sirve de eje estructurador para El pez de oro, y finalmente destaca la continuación actual de esta tradición en la novela Cuando Sara Chura despierte de Juan Pablo Piñeiro.

Sin abandonar el ámbito de las prácticas populares, Jorge Coronado propone una lectura de la música en la novela El Sexto de José María Arguedas, puesto que si para Arguedas la música pareciera ser expresión palpable de un espacio comunicativo y sonoro dentro del cual las tradiciones culturales andinas aún pueden ser oídas, en esta novela y su ubicación urbana, la música debe enfrentarse a un ambiente más hostil que en otras novelas de ambientación serrana, lo que transforma al espacio sonoro en uno de carácter controvertido y conflictivo. Además, según Coronado, la música en esta novela permite notar que ya en ella se perciben las inquietudes y problemas de la modernización y de la migración entre sierra y costa que caracterizarán la novela $E l$ zorro de arriba y el zorro de abajo.

Por su parte, también en relación con los movimientos migratorios, Dieter Ingenschay se concentra en la actual inmigración boliviana a la Argentina y en la manera en cómo

Revista Iberoamericana, Vol. LXXXI, Núm. 253, Octubre-Diciembre 2015, $925-935$ ISSN 0034-9631 (Impreso) 
las novelas de Bruno Morales (Sergio Di Nucci) Bolivia Construcciones y Grandeza boliviana enfocan este problema. Su lectura plantea el surgimiento en las literaturas más actuales de una "poética de las minucias" (Poetik der Belanglosigkeit), es decir, de novelas que -como sucede en este caso- se sitúan en los procesos migratorios actuales, pero que no tematizan el gran horizonte de la experiencia traumática que éstos procesos significan; es más, pareciera que mediante el juego de pseudónimos y plagios, estas novelas relativizan los principios con los cuales se interpreta a este tipo de obras a partir de la idea de un sujeto migrante o transfronterizo.

Roger Friedlein y Vicente Bernaschina Schürmann concentran sus colaboraciones en la literatura virreinal en cuanto componente histórico fundamental para el desarrollo heterogéneo y transandino de las literaturas en la región andina. Friedlein propone una lectura del extenso poema épico El Bernardo de Bernardo de Balbuena, deteniéndose en la composición del vuelo mágico que se realiza por sobre la cordillera de los Andes y que destaca las riquezas del continente, además del conocimiento geográfico ya existente a principios del siglo XVII. El análisis de Friedlein pone en evidencia que la región andina se revela ya imaginada por las ambiciones económicas de los poderes europeos, al igual que atrapada dentro de un planeta ya jerarquizado desde Europa.

Bernaschina, por su parte, se detiene en la composición de dos sonetos plurilingües en los preliminares de la traducción del Cancionero de Petrarca, realizada en el Virreinato del Perú por el portugués Enrique Garcés, para demostrar cómo desde un principio la literatura que se instala en la zona andina durante el periodo virreinal no traslada al Nuevo Mundo sólo a la literatura ibérica y al castellano como lengua del imperio, sino todo un conjunto de sistemas poéticos y lingüísticos europeos. Por una parte, esto marca el dominio absoluto de los códigos europeos en las prácticas literarias de la Corte, aunque por la otra, señala también la apertura de las lenguas a la traducción e influencias de otras lenguas, lo que siembra la posibilidad del ingreso futuro de las lenguas indígenas.

El volumen se cierra con la colaboración de Ottmar Ette, quien propone una lectura transandina de los Comentarios reales del Inca Garcilaso de la Vega, de El sueño del Celta de Mario Vargas Llosa y de Lost City Radio de Daniel Alarcón desde el marco de los TransArea Studies. La contribución de Ette muestra cómo desde principios del siglo XVII, la literatura peruana está funcionando constantemente dentro de un marco global mayor, representando experiencias y saberes de la vida, de la supervivencia y del convivir en distintas lógicas y en distintas lenguas.

Revista Iberoamericana, Vol. LXXXI, Núm. 253, Octubre-Diciembre 2015, $925-935$ ISSN 0034-9631 (Impreso)

ISSN 2154-4794 (Electrónico) 
BiBLIOGRAFÍA

Appadurai, Arjun. Globalization and Area Studies: The Future of a False Opposition. Amsterdam: Centre for Asian Studies Amsterdam, 2000.

Modernity at Large: Cultural Dimensions of Modernity. London/Minneapolis: U of Minnesota P, 1996.

Báez Hernández, Sonia et al., eds. Ir y venir: procesos transnacionales entre América Latina y el norte. Santiago de Chile: Bravo y Allende Editores, 2007.

Bernaschina Schürmann, Vicente. "Estudios transandinos: propuestas para viejos y nuevos diálogos poético-críticos”. Diálogos culturales en la literatura latinoamericana: Actas del XXXIX Congreso del Instituto Internacional de Literatura Latinoamericana (IILI). Consuelo Reverte Bernal, ed. Madrid: Verbum, 2014. 1630-1641.

Bosshard, Marco Thomas. "Estudios transandinos. Algunos planteamientos preliminares". Diálogos culturales en la literatura latinoamericana: Actas del XXXIX Congreso del Instituto Internacional de Literatura Latinoamericana(IILI). Consuelo Reverte Bernal, ed. Madrid: Verbum, 2014. 1642-1652.

Carggiolis, Cynthia. "Tejidos y anudados poéticos en la obra de Cecilia Vicuña". Memorias. XJornadas andinas de literatura latinoamericana (JALLA, Cali), 2012. $<$ http://jalla2012.univalle.edu.co/images/Contenido/pdf/Ponencias/53_Tejidos_ yAnudados_Poeticos_Cynthia_Carggiolis.pdf>. 1 dic. 2015.

Cornejo Polar, Antonio, Escribir en el aire: Ensayo sobre la heterogeneidad sociocultural en las literaturas andinas. Prólogo de Mabel Moraña, Bibliografía de Jesús Díaz Caballero. 1994. Lima-Berkeley: Centro de Estudios Antonio Cornejo Polar, Latinoamericana Editores, 2003.

La formación de la tradición literaria en el Perú. Lima: CEP, 1989.

"Para una teoría literaria hispanoamericana: A veinte años de un debate decisivo". 1992. Revista de Crítica Literaria Latinoamericana 25 (1999): 9-12.

Sobre Literatura y Crítica Latinoamericanas, Caracas: Ediciones de la Facultad de Humanidades y Educación. Universidad Central de Venezuela, 1982.

Cortés, Almudena y Alicia Torres, eds. Codesarrollo en los Andes: Contextos y actores para una acción transnacional. Quito: FLACSO, 2009.

Fernández Retamar, Roberto. "Algunos problemas teóricos de la literatura hispanoamericana". Para una teoría de la literatura hispanoamericana. Primera edición completa. Bogotá: Publicaciones del Instituto Caro y Cuervo, 1995. 88-134. Hall, Peter A. y Sidney Tarrow. "Globalization and Area Studies: When Is Too Broad Too Narrow?”. Chronicle of Higher Education 44 (1998): B4-B5.

Hernando Marsal, Meritxell. “Antropólogos/Antropófagos: perspectivas brasileñas del espacio andino". Memorias. X Jornadas andinas de literatura latinoamericana (JALLA, Cali), 2012. <http://jalla2012.univalle.edu.co/images/Contenido/pdf/

Revista Iberoamericana, Vol. LXXXI, Núm. 253, Octubre-Diciembre 2015, 925-935 ISSN 0034-9631 (Impreso)

ISSN 2154-4794 (Electrónico) 
Ponencias/158_Antropologos_Antropofagos_Meritxell_Hernando_Marsal.pdf $>$. 1 dic. 2015.

Morin, Françoise y Roberto Santana, eds. Lo transnacional. Instrumento y desafio para los pueblos indigenas. Quito: Abya-Yala, 2002.

Noriega Bernuy, Julio. Caminan los Apus: escritura andina en migración. Lima: Pakarina Ediciones y Galesburg, Illinois: Knox College, 2012.

Portes, Alejandro, Luis Guarnizo y Patricia Landolt, eds. La globalización desde abajo: Transnacionalismo inmigrante y desarrollo: la experiencia de Estados Unidos y América Latina. México D.F.: FLACSO, 2003.

Pries, Ludger, ed. Rethinking Transnationalism. The Meso-link of Organizations. London: Routledge, 2008.

Rama, Ángel. Transculturación narrativa en América Latina. México D.F.: Siglo XXI, 1982.

Rincón, Carlos. El cambio actual de la noción de literatura y otros estudios de teoría y crítica latinoamericana. Bogotá: Instituto Colombiano de Cultura, 1978.

Rojo, Grínor. "Ángel Rama, Antonio Candido y los conceptos de sistema y tradición en la teoría crítica latinoamericana moderna". Caligrama 12 (2007): 7-33.

Vertovec, Steven. "Conceiving and Researching Transnationalism". Ethnic and Racial Studies 22/2 (1999): 447-462.

Zevallos Aguilar, Ulises Juan. "Hacia una topografía del archipiélago cultural andino". Socialismo y Participación 87 (2000): 101-110.

Las provincias contraatacan: regionalismo y anticentralismo en la literatura peruana del siglo XX. Lima: Universidad Nacional Mayor de San Marcos, Ediciones del Vicerrectorado Académico, 2009. 
